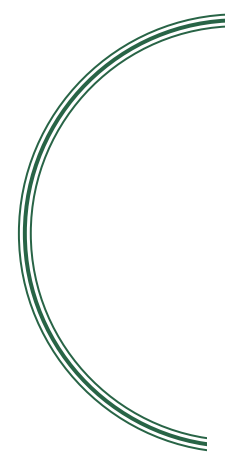

\title{
Positive Perspectives from Proton Therapy
}

\author{
Emma Louise Walton \\ Staff Writer at the Biomedical Journal, 56 Dronningens Gate, 7012 \\ Trondheim, Norway
}

In this issue of the Biomedical Journal, we take a look at some of the benefits of proton therapy, which is an emerging technique in cancer treatment and highlight an animal study, showing that a common fruit ripening agent is toxic when used in excessive doses. Finally, this issue includes reports that shed light on the genetics of stroke and childhood leukemia. (Biomed J 2015;38:361-364)

Key words: ethephon, head and neck cancer, liver cancer, proton therapy

\section{SPOTLIGHT ON REVIEWS - Positive Perspectives from Proton Therapy}

X -rays have been the mainstay of radiotherapy for more than a century. Although the techniques designed to target $\mathrm{X}$-rays to the site of the tumor have improved remarkably over the past years, the principle and hence problem of this treatment remains the same. X-rays are high-energy photons that distribute their energy linearly throughout tissues, with the highest dose at the point of entry and a sizeable residual dose after the tumor. This means that in cancer patients with inoperable tumors in vulnerable regions such as the brain; the effective dose of radiation must be reduced to avoid damaging healthy tissue, which limits the effectiveness of the treatment. At present, an emerging technique called proton therapy may offer hope to such patients with some even crossing oceans to reach it. ${ }^{[1]}$

In proton therapy, large particle accelerators are used to generate and focus protons into a beam directed at the patient's tumor. As protons move through tissues, they slow down, interact with electrons, and release energy. The site of maximal energy deposition is called the Bragg peak [Figure 1], which for protons, occurs immediately before the particle comes to rest. Physicians can ensure that the Bragg peak is reached at the site of the tumor, such that the proton beam causes maximal damage to tumor cells while sparing healthy tissues behind the tumor. There are currently around 50 operational or planned proton therapy centers around the world. ${ }^{[2]}$ With over half of these centers having opened their doors within only the past 5 years, there is still a great need for clinical studies assessing the effectiveness of proton therapy for different types of cancers. In this issue of the Biomedical Journal, Kao et al.${ }^{[3]}$ discuss the potential benefits of proton therapy for Taiwanese cancer patients, who can now be offered this treatment in their own country as of 2014. The prevalence of cancer types differs between Western and Asian countries with Taiwan having a particularly high number of hepatocellular carcinoma and head and neck cancer cases. Hong summarizes literature reports concerning proton therapy for these cancers. He estimates that up to $15-20 \%$ of Taiwan's 10,000 annual hepatocellular carcinoma patients could benefit from proton therapy, which was reported to have a success rate of $81-96 \%$ in Japanese patient series. ${ }^{[4-6]}$ For head and neck cancer, the benefit of proton therapy may be even greater, as around 90\% of Taiwan's 4000 annual cases receive radiotherapy ${ }^{[7]}$ Although more studies are still required to assess the efficacy of the latest techniques in proton therapy in the population, this treatment provides the clear advantage of sparing the delicate tissues of the head and neck and thus reducing the need for nasogastric tube feeding. ${ }^{[8]}$

Finally, Tung describes some of the technical

DOI: $10.4103 / 2319-4170.167058$ 


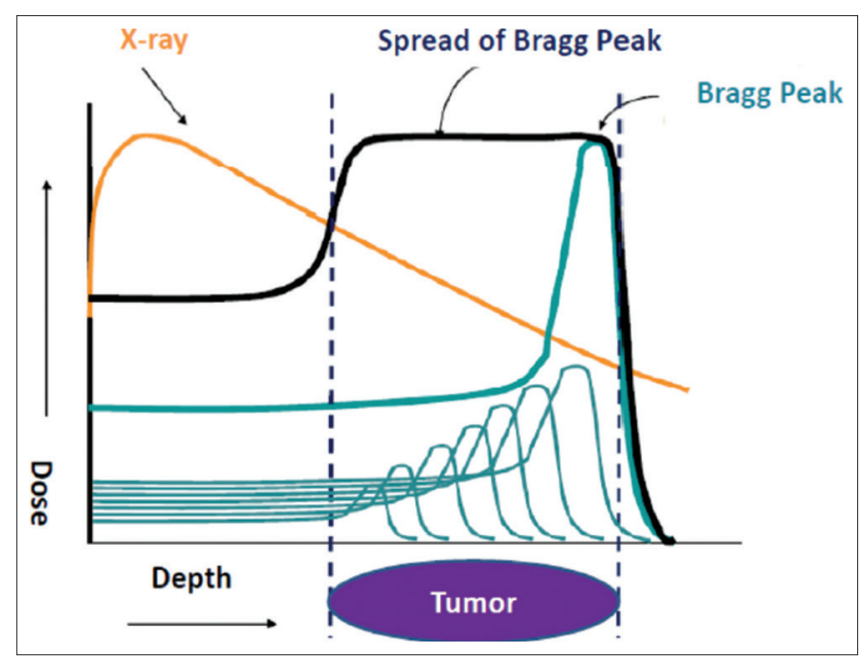

Figure 1: Comparison of delivered dose between photon (X-ray) and particle (proton) beams. Figure kindly provided by Ji-Hong Hong.

aspects of administering proton therapy and summarizes biophysical models used to determine the relative biological effectiveness of protons at different depths. ${ }^{[9]}$ The methods presented here provide a basis to calculate the yield of DNA damage caused by particles in the beam and show that as compared to a photon beam, proton beams show a higher absorbed dose and induce complex types of DNA damage enabling lower doses to be used to achieve the same biological effect.

Thus, with the refining of proton treatment techniques and the opening of new proton therapy centers, it seems that proton therapy can offer many more patients a "positive" prognosis in the years to come.

\section{SPOTLIGHT ON ORIGINAL ARTICLES - Ripening Agent Causes Liver Damage in Rats in Excessive Doses}

An old saying goes "an apple a day keep the doctor away." This phrase has since been updated to the less catchy, but more relevant World Health Organization guideline, " $400 \mathrm{~g}$ of fruit or vegetable per day helps to prevent chronic diseases such as heart disease, cancer, diabetes, and obesity." ${ }^{[10]}$ The message, however, remains unchanged: Fruit and vegetables are good for your health. However, what about fruit and vegetables that is mass-produced to keep up with the increasing demands of a growing society? In this issue of the Biomedical Journal, Bhadoria et al. ${ }^{[11]}$ show that ethephon, a chemical used in fruit ripening, has toxic effects on the liver in rats.

Chemical ripening agents including ethylene, ethane, calcium carbide, and ethephon are commonly used for artificial ripening. Ethephon, in particular, is widely used because of its broad spectrum of activities: It promotes, ripening, flower induction, fruit coloration, and fruit abscission. ${ }^{[12]}$
In 2006, the Environmental Protection Agency concluded with "reasonable certainty that no harm to any population subgroup will result from exposure to ethephon." ${ }^{[13]}$ Nonetheless, some isolated studies report toxic effects associated with this chemical, including chromosomal aberrations during pregnancy in mice ${ }^{[14]}$ and impaired motor activity and vocalization in rats. ${ }^{[15]}$

To study further the effect of ethephon in vivo, Bhadoria et al. focused on the primary site for the detoxification of chemicals, the liver. They divided 20 rats into two groups: An experimental group that received $200 \mathrm{mg} / \mathrm{kg}$ body weight of ethephon per day for 14 days by oral gavage, and a control group that was subjected to oral gavage without ethephon. Animals in the experimental group showed behavioral changes during the experiment, including hypoactivity and decreased their food intake. Moreover, histological analysis revealed that hepatocytes were significantly smaller in the ethephon-treated rats than in control rats. The nuclei of hepatocytes were also smaller in the experimental group, suggesting reduced functional activity. Finally, the parenchyma showed inflammatory infiltrations and the central vein; sinusoids and bile canaliculi were dilated in ethephon-treated rats. Thus, ethephon caused inflammatory and degenerative changes in the liver associated with cholestasis, suggestive of toxic hepatitis.

Before anyone goes rushing out into the garden to plant their own fruit and vegetables, it is worth noting that the acceptable daily intake of ethephon in humans is a mere $0.05 \mathrm{mg} / \mathrm{kg}$ body weight, that is, 4000 times less than that used in this study. ${ }^{[16]}$ Perhaps, we should be more concerned about what ripening agents do to our fruit, and not the chemicals themselves. In 2012, Hakim et al. ${ }^{[17]}$ collected pineapple and banana samples from Bangladeshi markets and compared naturally ripened fruit with fruit ripened with ethephon. They found that chemically ripened fruit had a higher sugar content and lower beta-carotene content than naturally ripened fruit. Still, more studies are required to confirm these findings, and with autumn approaching and apples aplenty, do not forget that old saying.

\section{ALSO IN THIS ISSUE: REVIEWS - Caveolae in Cancer}

Caveolae (literally "little caves") are small invaginations of the plasma membrane with roles in cell signaling, membrane trafficking and were recently linked to response to mechanical stress. ${ }^{[18]}$ Lamaze and Torrino discuss the emerging role of caveolae in cancer in the context of their newly discovered function in cell mechanics. ${ }^{[19]}$

\section{The Two Faces of Nitric Oxide in Cancer}


Nitric oxide is an enigmatic molecule in cancer. It can have either pro- or anti-tumor activities, depending on its intracellular concentration, compartmentalization, and cell sensitivity. In this review, Monteiro et al. ${ }^{[20]}$ describe this dual role within the context of two oncogenic signaling pathways.

\section{ORIGINAL ARTICLES - Measuring the Characteristics of Proton Beams}

Cai et al..$^{[21]}$ examine in more detail the depth dose characteristics of proton beams using the particle therapy simulation framework Monte Carlo technique. Similarly, Lee et al. ${ }^{[22]}$ use Monte Carlo N-Particles Transport Code to simulate proton dose distributions in a water phantom. These data may serve as the basis for clinical guidelines in proton therapy.

\section{CYP3A5 Genetic Variant Linked to Risk of Childhood Leukemia}

Acute lymphoblastic leukemia (ALL) is the most common cancer in childhood. Polymorphisms in CYP3A5, which is involved in the metabolism of drugs and pro-carcinogens, have been associated with the risk of ALL, in some, but not all, studies. In their meta-analysis of five case-control studies including 1070 cases and 1125 controls in total, Ma et al. ${ }^{[23]}$ lay this controversy to rest and show that the CYP $3 \mathrm{~A} 5 * 3$ allele, which confers low expression, is associated with childhood ALL in Caucasian populations.

\section{Elucidating the Genetics of Stroke}

Stroke is linked to many environmental risk factors, which complicates the understanding of the genetics of this disease. Despite this, some susceptibility genes have been identified, including PRKCH, which encodes a protein kinase implicated in the progression and development of atherosclerosis. ${ }^{[24]}$ A nonsynonymous SNP in PRKCH increases the activity of the protein kinase and is common in Asian populations. In this retrospective study of 206 Taiwanese ischemic stroke patients and 337 controls, Chen et al. ${ }^{[25]}$ report that this polymorphism is associated with lacunar infarction, even when adjusting for co-founding factors, but is not associated with other types of stroke.

\section{Hippocampal Sparing Preserves Memory Function during Whole Brain Radiotherapy}

Whole brain radiotherapy (WBRT) with or without surgical resection is the treatment of choice for patients faced with the dismal diagnosis of metastatic brain lesions. Although WBRT generally preserves neurocognitive func- tions, it can also paradoxically lead to their decline, possibly by impairing neurogenesis in the hippocampus. ${ }^{[26]}$ Lin et al. ${ }^{[27]}$ show prospectively in 25 patients that sparing the hippocampus during WBRT can prevent functional decline in memory during treatment.

\section{A New Method for Predicting the Size of Unerupted Teeth}

The optimal planning of orthodontic treatment depends on accurate predictions of the size of unerupted permanent teeth during the mixed dentition stage. Several methods have been proposed for this purpose, but they remain to be validated in many ethnic populations. Juneja et al. ${ }^{[28]}$ test three of these methods in the North Indian population and find that all three overestimate the size of unerupted permanent canines and premolars. They thus propose a new method tailored to this population.

\section{Defining the Best Approach for Medical Record Audits}

Accurate and up-to-date medical records are essential for the high-quality care, and regular audits of these records are necessary to determine where improvements can be made. Huang et al. ${ }^{[29]}$ investigate the difference between internal and external auditing of medical records kept by physicians applying for promotion in a Taiwanese hospital and find that external auditing provides the most reliable results.

\section{LETTERS TO THE EDITOR - Questioning the Impact of Journal Impact Factor on Research}

Kanchan and Krishan ${ }^{[30]}$ comment on a recent Biomedical Journal article examining how impact factor is affecting our research. ${ }^{[31]}$

\section{Clinicopathological Features of Gastric Hepatoid Adenocarcinoma}

Sureka et al.$^{[32]}$ point out some additional features of gastric hepatoid adenocarcinoma to supplement those described by Lin et al. ${ }^{[33]}$ in a recent issue of the Biomedical Journal.

\section{Financial support and sponsorship}

Nil.

\section{Conflicts of interest}

There are no conflicts of interest. 


\section{REFERENCES}

1. Available from: http://www.scienceblog.cancerresearchuk.org/2013/09/16/ proton-therapy-is-coming-to-the-uk-but-what-does-it-mean-for-patients/. [Last accessed on 2015 Sep 30].

2. Available from: http://www.proton-therapy-today.com/ where-to-get-pt/. [Last accessed on 2015 Sep 30].

3. Kao WH, Shen YL, Hong JH. What are the potential benefits of using proton therapy in Taiwanese cancer patients? Biomed J 2015;38:391-8.

4. Kawashima M, Furuse J, Nishio T, Konishi M, Ishii H, Kinoshita T, et al. Phase II study of radiotherapy employing proton beam for hepatocellular carcinoma. J Clin Oncol 2005;23:1839-46.

5. Chiba T, Tokuuye K, Matsuzaki Y, Sugahara S, Chuganji Y, Kagei K, et al. Proton beam therapy for hepatocellular carcinoma: Aretrospective review of 162 patients. Clin Cancer Res 2005;11:3799-805.

6. Komatsu S, Fukumoto T, Demizu Y, Miyawaki D, Terashima K, Sasaki $\mathrm{R}$, et al. Clinical results and risk factors of proton and carbon ion therapy for hepatocellular carcinoma. Cancer 2011;117:4890-904

7. Health Promotion Administration MOHaW. Cancer Registry Annual Report, 2011. Taiwan; 2014.

8. Frank SJ, Rosenthal DI, Ang K, Sturgis EM, Chambers MS, Gunn GB, et al. Gastrostomy tubes decrease by over 50\% with Intensity Modulated Proton Therapy (IMPT) during the treatment of oropharyngeal cancer patients: A case control study. Int J Radiat Oncol Biol Phys 2013;87:S144.

9. Tung CJ. Microdosimetric relative biological effectiveness of therapeutic proton beams. Biomed J 2015;38:399-407.

10. Availble from: http://www.who.int/dietphysicalactivity/fruit/ en/. [Last accessed on 2015 Sep 30]

11. Bhadoria P, Nagar M, Bahrioke V, Bhadoria AS. Effect of ethephon on the liver in albino rats: A histomorphometric study. Biomed J 2015;38:421-7.

12. Moore TC. Ethylene: Biochemistry and Physiology of Plant Hormones. $2^{\text {nd }}$ ed. New York, Heidelberg, Berlin: Springer, Verlag; 1989. p. $228-59$

13. Availble from: http://www.epa.gov/pesticides/reregistration/ ethephon/. [Last accessed on 2015 Sep 30].

14. El-Raouf AA, Girgis SM. Mutagenic, teratogenic and biochemical effects of ethephon on pregnant mice and their fetuses. Glob Vet 2011;6:251-7.

15. Beyrouty P. A Time of Peak Effects Study of a Single Orally Administered Dose of Ethephon in Rats. Unpublished Report BRL Project ID 97411, Bio-Research Laboratories Ltd., Senneville, Quebec, Canada. Submitted to WHO by Aventis CropScience SA, Secteur Agro, Lyon, France; 1996.

16. Available from: http://www.inchem.org/documents/jmpr/ jmpmono/2002pr05.htm. [Last accessed on 2015 Sep 30].

17. Hakim MA, Obidul Huq AK, Alam MA, Khatib A, Saha BK, Zaidul IS, et al. Role of health hazardous ethephone in nutritive values of selected pineapple, banana and tomato. J Food Agric Environ 2010;10:247-51.
18. Sinha B, Köster D, Ruez R, Gonnord P, Bastiani M, Abankwa D, et al. Cells respond to mechanical stress by rapid disassembly of caveolae. Cell 2011;144:402-13.

19. Lamaze C, Torrino S. Caveolae and Cancer: A New Mechanical Perspective. Biomed J 2015;38:367-79.

20. Monteiro HP, Costa PE, Reis AK, Stern A. Nitric oxide: Protein tyrosine phosphorylation and protein S-nitrosylation in cancer. Biomed J 2015;38:380-8.

21. Cai SY, Chao TC, Lin MJ, Tung CJ, Lee CC. Depth dose characteristics of proton beams within therapeutic energy range using the particle therapy simulation framework (PTSim) Monte Carlo Technique. Biomed J 2015;38:408-13.

22. Lee CC, Lee YJ, Chen SK, Chiang BH, Tung CJ, Chao TC. MCNPX simulation of proton dose distributions in a water phantom. Biomed J 2015;38:414-20.

23. Ma LM, Liu HC, Ruan LH, Feng YM. CYP 3 A $5 * 3$ genetic polymorphism is associated with childhood acute lymphoblastic leukemia risk: A meta-analysis. Biomed J 2015;38:428-32.

24. Kubo M, Hata J, Ninomiya T, Matsuda K, Yonemoto K, Nakano T, et al. A nonsynonymous SNP in PRKCH (protein kinase $\mathrm{C}$ eta) increases the risk of cerebral infarction. Nat Genet 2007;39:212-7.

25. Chen YC, Huang CJ, Chen P, Wu YR, Shie SS, Chen ST, et al. Protein Kinase $\mathrm{C} \eta$ Polymorphism and the susceptibility to ischemic stroke in the Taiwan population. Biomed J 2015;38:433-8

26. Raber J, Rola R, LeFevour A, Morhardt D, Curley J, Mizumatsu S, et al. Radiation-induced cognitive impairments are associated with changes in indicators of hippocampal neurogenesis. Radiat Res 2004; $162: 39-47$

27. Lin SY, Yang CC, Wu YM, Tseng CK, Wei KC, Chu YC, et al Evaluating the impact of hippocampal sparing during whole brain radiotherapy on neurocognitive functions: A preliminary report of a prospective phase II study. Biomed J 2015;38:439-49.

28. Juneja S, Mahajan N, Kaur H, Verma KG, Sukhija M, Bhambri E. Comparative evaluation of three mixed dentition analyses and formulation of regression equations for North Indian population: A cross-sectional study. Biomed J 2015;38:450-5.

29. Huang CD, Jenq CC, Ou LS, Chen AC, Chan SH, Huang JL, et al. Medical record review for faculty promotion: A cohort analysis. Biomed J 2015;38:456-61.

30. Kanchan T, Krishan K. Questioning the impact of journal impact factor on research? Biomed J 2015;38:462.

31. Rawat $\mathrm{S}$. How is impact factor impacting our research? Biomed $\mathrm{J}$ $2014 ; 37: 415-6$

32. Sureka B, Bansal K, Arora A. Clinicopathological features of gastric hepatoid adenocarcinoma. Biomed J 2015;38:463.

33. Lin CY, Yeh HC, Hsu CM, Lin WR, Chiu CT. Clinicopathologial features of gastric hepatoid adenocarcinoma. Biomed J 2015;38:65-9.

This is an open access article distributed under the terms of the Creative Common Attribution-NonCommercial-ShareAlike 3.0 License, which allows others to remix, tweak, and build upon the work non-commercially, as long as the author is credited and the new creations are licensed under the identical terms. 